\title{
A teOria FILOSÓFICA do DIREITo de HANS KELSEN E SEUS CONTORNOS DE LEGITIMIDADE
}

\author{
[The PHilosophical Hans Kelsen's Right Theory AND ITS Ligitimate OUTLINES]
}

\author{
Newton de Oliveira Lima *
}

Resumo: A partir da consideração de Immanuel Kant de que todo Estado deve se fundar numa Constituição republicana, e da formulação de Hans Kelsen de que os valores políticos básicos que sustentam a atividade legislativa de um Estado são a liberdade individual, a segurança e a ordem, deve-se conceber uma ligação fundamental entre republicanismo, que implica no respeito incondicional ao Direito como condição de possibilidade da ordem pública e liberalismo como necessidade de liberdade à realização do processo legislativo. Esse 'republicanismo liberal' kantiano-kelseniano necessita de uma relação normativa que proteja a atividade legislativa, assegurando a Democracia; para além da ideia de normatividade, torna-se inviável pensar um Estado democrático, pensar, assim, a possibilidade de existência (ontologia) e a legitimidade (consenso e decisão de realização) do Direito é avaliar como a relação entre liberdade, legalidade e produção de normas se estabelece, na pressuposição sempre objetiva de pensar a ideia da norma em si, para além de toda positividade concreta (histórica e sociológica) - a norma fundamental de Kelsen, a 'forma pública' universal do Direito para Kant. Existe um co-pertencimento entre Estado de Direito e normativismo jurídico. Para se pensar um Estado de Direito necessita-se do fundamento
Abstract: From the consideration of Immanuel Kant that every State must be based on a republican constitution, and Hans Kelsen formulation of the basic political values that underpin the legislative activity of a State are individual freedom, security and order, must devise a fundamental connection between republicanism, which implies the unconditional respect for the Law as a condition of possibility of public order and liberalism as the need for freedom to carry out the legislative process. This 'liberal republicanism' Kantian-Kelsen needs a normative relationship to protect the legislative action, protect from democracy; beyond normativity idea, it is not feasible to think a democratic State, thinking, well, the possibility of existence (ontology) and legitimacy (consensual and decision realization) of the Law is to assess how the relationship between freedom, legality and production standards is established, the always objective presupposition to think the idea of the standard itself, beyond all concrete positivity (historical and sociological) - the essential norm of Kelsen, the universal public order of Law from Kant. There is a co-belonging between State of Law and legal normativism. To think of State of Law needs to be the foundation of a legal system, either rational discourse enabler of morality, for Kant, or as to Kelsen the logical

* Doutor em Filosofia. Doutorado Sandwich em Filosofia pela Universidad de Buenos Aires (2014). Professor Adjunto do Departamento de Ciências Jurídicas do Centro de Ciencias Jurídicas da Universidade Federal da Paraiba. Líder do Grupo de Pesquisa: Filosofia do Direito e Pensamento Político. Pesquisador do Centro de Pesquisas em Democracia-CEPEDE, e Membro do Núcleo de Direitos Humanos da Univesidade Federalda Paraiba.m@ilto: newtondelima@gmail.com 
de um sistema normativo, seja discursivo racional possibilitador da moral, para Kant, ou como para Kelsen a unidade lógica da ideia do sistema de normas, expressa na Grundnorm (norma fundamental).

Palavras-chave: Estado; dreito; unit standard idea of system of norms expressed in Grundnorm (essential norm).

KEYWORDS: State; law; legitimacy; liberty

legitimiação; liberdade

\section{INTRODUÇÃO: ESTADO E SISTEMA JURÍDICO EM KELSEN}

A bordaremos a Filosofia do Direito por sua teoria jusfilosófica mais importante e célebre, a "Teoria Pura do Direito" do austríaco de ascendência judaica Hans Kelsen (1881-1973). A teoria de Kelsen nasce em um dos mais acirrados momentos de choque de valores no cenário europeu, a primeira metade do século $\mathrm{XX}$, onde estava em perigo a ordem jurídica pelas dissensões políticas. O quadro de conflito entre liberalismo, socialismo e nacionalismo levou a interpretações políticas do Direito que abalaram a estrutura do Estado liberal e positivista.

As jurisprudências conflitantes foram influenciadas por uma série de valores políticos que quiseram se posicionar de fora do contexto da teoria do ordenamento jurídico, o qual se valia de uma esfera de proteção normativa sob a ideologia do julgamento neutro do juiz. Ao criticar o ideário comunista Kelsen ${ }^{1}$ deixa claro sua preocupação com a tensão que os conflitos político-ideológicos causam sobre o Direito:

El caráter ideológico de la teoria soviética del derecho es consecuencia inevitable del principio marxista - contrario al postulado antiideológico- de que la ciência social em geral y la ciencia del Estado y del derecho em particular tienen que ser políticas, es decir, tienen que traducirse en fórmulas que pueden ser usadas em la lucha política de um grupo contra outro. El deplorable status de la teoria soviética, degradada a la condición de sirvienta del gobierno soviético, debe ser uma sombría advertência, para quienes se dedican a las ciencias sociales, de que la verdadeira ciencia social es posible a condición de que sea independiente de la política.

O Estado para Kelsen deveria se legitimar através de sua própria forma de produção de normas e seu ordenamento jurídico lógico e sistêmico-científico. Assim, a crítica radical de Kelsen ao jusnaturalismo assume contornos anti-metafísicos amplos contra quaisquer justificativas ou inspirações não lógico-formais de justificação da existência do Estado e do Direito. Esse limite de confronto entre uma teoria formal e uma teoria da decisão deve ser estruturado no âmbito da própria "Teoria Pura do Direito".

O Direito como sistema formal implica uma pressuposição de que a norma é o critério de avaliação de outras normas, mas como uma teoria objetiva completa não é possível, é preciso recair a um nível de decisão (pessoal) para efetivar a própria validade, o que implica numa fuga da própria validade e na adesão a uma decisão ${ }^{2}$ que efetive a norma jurídica. Kelsen tocou nesse ponto no Capítulo VIII da sua "Teoria Pura do Direito" e deixou às claras o paradoxo decisionista existente no Direito (o formalismo das normas e a efetivação real de seu texto como comando destinado à realidade social).

É onde irá surgir a metáfora explicativa da 'moldura': a norma é uma circunscrição restrita ao que o intérprete decidir, apto ao estabelecimento do sentido, a lei será sempre um caso de interpretação pelo aplicador. Este é investido de uma autoridade competente legalmente e capaz de decidir entre os objetivos da lei: o que a lei prescreve não é puramente formal, ou seja, não é um comando já dado, mas deve ser interpretado.

A norma jurídica é uma moldura que carece da efetivação de um conteúdo regulado, o intérprete deve sempre decidir sobre os sentidos de aplicação da norma. O que garante a 
objetividade do Estado de Direito é o fato de se constituir com base em decisões tomadas como referentes a leis formais que são interpretadas por decisões, as quais se confirmam em decisões anteriores ${ }^{3}$.

O sistema formalista do direito constitucional de Kelsen afere a coerência lógica da normatividade, não a proteção à autoridade que decide sobre a norma, por isso Schmitt criticou o legalismo constitucional kelseniano ${ }^{4}$.

Kelsen mantém o coerentismo de uma teoria lógica do Direito ao deixar conduzir o ato de vontade por uma estruturação racional sistêmica. O papel da razão é o de sistematizar os quadros possíveis da vontade do intérprete sobre a norma, isto é, do exercício de seu poder sobre a concessão de sentido normativo.

Outro elemento central em Kelsen é a teoria da coação e da previsão das sanções da categoria da ilicitude: sem sanção válida não há Direito ${ }^{5}$. A garantia da licitude é o próprio cumprimento da pacificação pelo Direito. Mas isso de um modo indireto, porque o Direito não visa valores de modo direto, que são fins políticos ou arbitrários aos indivíduos que exercem o poder jurídico, e este conforma suas representações de valores ao que o ordenamento objetivamente prevê e tutela.

Para a "Teoria Pura do Direito" a conduta humana sujeita-se a sanções jurídicas; quando se não prescreve determinada sanção para certo tipo de conduta esta pode ser considerada permitida pelo ordenamento. Isso se adotando uma cláusula geral como pressuposto lógico-jurídico: tudo que não é proibido, é permitido.

Existe um grau de liberdade dos indivíduos em relação ao sistema jurídico, pois não é possível para o ordenamento regular a totalidade da vontade humana, havendo sempre um campo de ausência de coação, o que Kelsen enquadra como uma esfera de liberdade irredutível, porque subjetiva ${ }^{6}$.

Todavia, é política e moralmente necessária a adoção de um conteúdo críticoracional à norma hipotética fundamental de Kelsen, para que a unidade do sistema jurídico não seja apenas formal e validativa, afastando o Estado da possibilidade de uma assimilação autoritária por eventuais grupos de poder não democráticos, evitando como diz Arnaldo Vasconcelos, que a Política se resuma ao uso da força ${ }^{7}$; a defesa da organização social como ordem centralizada coativamente busca reduzir a Política à atividade policial. Direito e Estado idênticos significa que o uso da força garante a ordem social centralizada ${ }^{8}$.

Os problemas da dignidade da pessoa e da liberdade seriam para Kelsen modelos de um padrão de Política humanista que já não interessariam à objetividade científica da teoria pura $^{9}$, a qual seria apenas uma ordem centralizada de controle social assegurada pela possibilidade do uso da coerção física.

Kelsen prossegue, dessa forma, a tradição do mecanicismo da Política moderna, que vem de uma visão legalista com Napoleão e sus sistema centrado em um Direito formal, passa pelo Estado policial prussiano e seus contornos militaristas de imposição da força (séc. XVIII), até o Estado utilitarista controlador dos desejos e dos interesses, redutor da dignidade humana a uma planificação da vida para assegurar felicidade, que consistiria em ganhar prazer e evitar a dor (séc. XIX) ${ }^{10}$.

Entre formas de controle explícitas, pela coerção, e implícitas, pela utilização do poder simbólico, o Estado moderno não abriu suficientes espaços de discussão de seus próprios fundamentos - o debate sobre a legitimação continua em aberto. Mas a legitimação pela força não é suficiente, mesmo com a garantia da razão técnica capaz de poupar um princípio de economia de esforço de potências de ação.

A construção do Estado é análoga à construção de uma máquina, ela requer esforço concentrado, força empregada tecnicamente por uma racionalidade instrumental. Como aponta Vasconcelos, Kelsen chamou isso de "princípio de um valor ótimo", a construção do Direito pela norma fundamental seria análogo ao princípio da economia de forças adotado por Ernst Mach na Física"1. O ideal de um Estado "mecânico" formado por uma série de atos conexos normativos, um grande corpo artificial como ideal de racionalidade técnica acompanha o pensamento moderno desde Hobbes, segundo Schmitt ${ }^{12}$.

A crítica política a Kelsen seria pela supressão da soberana, que Hobbes mantém de Bodin e da "Teoria do Direito Divino dos Reis" e que Kelsen suprimiü ${ }^{13}$ com seu apelo à 
legitimação do Estado com base em normas puras e sua auto-organização. Para Schmitt soberano é aquele que decide sobre o estado de exceção, um poder absoluto de pôr e suspender um ordenamento jurídico ${ }^{14}$.

Como sistema de organização social o Direito implica não uma justificação ética para Kelsen, ele não requer que a ordem jurídica tenha um fundamento moral, a diferença entre a ordem jurídica e a 'ordem de salteadores' é que essa última para Kelsen ${ }^{15}$ não possui a sanção normativo-estatal vinculada a uma autoridade reconhecida para aplicá-la, portanto não é uma ordem coercitiva válida.

O sistema jurídico exerce pela eficácia de suas sanções uma pacificação social que busca a segurança coletiva. No entanto, não se pode tratar tal eficácia como um elemento de justificação do Direito a partir da problemática axiológica, buscando identificar, por exemplo, um valor de justiça absoluto, que é sempre relativo ao sistema jurídico ao qual se refere e à consciência do intérprete autorizado por lei a aplicar a norma.

O sistema jurídico não pode deixar de comportar sanções em caso de descumprimento de seus preceitos, porque se isso ocorresse, atingir-se-ia uma situação crítica de descumprimento das normas e não validade do sistema. Dessa forma, mesmo os deveres jurídicos que aparentemente não possuem sanção, inclusive as normas procedimentais, vinculam-se indiretamente ou como consequência de sua aplicabilidade a normas portadoras de sanção ${ }^{16}$.

Assim, a norma jurídica possui uma interligação com a sanção, o que assegura a eficácia do sistema jurídico como um todo e, como tal, possui uma função coativa, presente mesmo nas denominadas "normas jurídicas autônomas", que servem apenas para auxiliar na eficácia ou interpretação de outras normas. Um sistema jurídico é um conjunto de normas asseguradas por sanções que se interligam mediante um processo lógico de relação estabelecido dentro de um quadro funcional de competências definidas legalmente. O Estado é uma organização institucionalizada de normas que definem competências e estas possibilitam práticas de poder.

Assim, a autopoiese ou auto-produção do sistema de normas gerará uma ontologia em si, uma ordem normativa pura, pressupostamente sem fundamentos de legitimação que não sua própria auto-organização; o hermeneuta do Direito, sem apelar em qualquer sentido para a concepção de autonomia moral do sujeito, portanto anti-kantianamente ${ }^{17}$, detectará o sentido instrumental (meio-fim) da norma para o legislador ou a dotará de sentido de acordo com sua volição - essa é a posição do 'último Kelsen', a fase que vai da década de 60 até sua morte em 1973 nos EUA, sob forte influência do realismo do pensamento jurídico norteamericano. ${ }^{18}$

Um dos grandes pontos de conflito do pensamento kelseniano, todavia, é o conceito de eficácia, onde se pode observar a tensão fático-normativa na qual Kelsen presumiu resolver com a solução lógica ao longo da evolução de seu pensamento: se uma norma foi produzida dentro do devido processo legislativo e vigora, também deve ser eficaz; ou seja, deve produzir efeitos jurídicos válidos, mas nem sempre a lógica normativa do dever-ser é compatível com a garantia de seus efeitos práticos (reais ou empírico-naturais-sociais).

O realismo jurídico ao apelar para valores sociais aderiu a uma concepção metafísica de realidade que seria desejada pela comunidade, pretendendo substituir a norma fundamental de Kelsen pela "norma básica" social. O Direito válido para os realistas seria a ideia de um sentido normativo aplicado pelo juiz e sua atividade de poder ao aplicar e interpretar o que está previsto no texto legal. Para os realistas normas jurídicas o são por sua aplicação por um juiz e não por sua previsão formal no ordenamento jurídico.

Todavia, a "norma básica" realista não é uma norma jurídica, uma norma válida de acordo com o processo de produção de normas, mas sim uma norma empírica, sociológica, sob a influência do empirismo dos padrões sociais que influenciam o Direito e das ideologias de decisão empregadas pelo juiz ao decidir o que é o Direito efetivo ${ }^{19}$.

Barzotto associou o pensamento de Ross e Kelsen no âmbito de seu empirismo ou historicismo axiológicos, na ideia de uma produção do Direito a partir da tensão entre fatos e valores $^{20}$, mas a crítica kantiana e logicista recai sobre ele: isso não seria um retrocesso ao que Kant estabeleceu em termos de separação metodológica entre Direito e Moral, entre 
normatividade e facticidade, enfim, entre Ser e Dever-Ser?

Mesmo o Direito Comum inglês de caráter empírico e histórico na legitimação de sua normatividade, pode ser interpretado kelsenianamente porque se pode abstrair a norma fundamental como pressuposto de coerência do sistema, e encontra na Constituição vigente reconhecida como tal pela vontade política dominante na nação, sua esfera de regulação prática, associado à norma fundamental como pressuposto da unidade lógica do sistema normativo. Sem o pressuposto da coerência sistêmica não existe Direito, mas tão somente a partir da metodologia kantiana que Kelsen adota em 1934 na "Teoria Pura do Direito" da divisão entre aquilo que se projeta como dever (Sollen), e aquilo que meramente se deseja, como algo que "tem que ser" (Müssen).

A conduta fixada pelas normas dirige-se aos cidadãos do Estado e seu cumprimento no domínio da vontade subjetiva, porém o poder de normatização do Estado pode colocar sanções em caso de descumprimento do comando da norma pelos cidadãos ${ }^{21}$. Regular a conduta humana pela norma jurídica significa prescrever a realização ou a omissão de um determinado ato pelo cidadão ${ }^{22}$, mas a vontade política de obedecer ao Direito não seria anterior a este, sendo o que lhe conferiria limite de ação e pressuposto de legitimação?

\section{DiREITO E POLÍTICA}

Para Kelsen a ordem jurídica implica num monopólio do uso da força sobre a comunidade dos indivíduos sujeitos à coação estatal, isto é, somente o Estado pode empregar a força coercitiva para repelir o descumprimento da norma jurídica. Em uma perspectiva kantiana seria o pressuposto lógico-normativo, portanto, que assegura que o poder possa ser organizado como um sistema de normas.

Como consequência, esse domínio do Direito estatal fez do cidadão um anônimo no contexto do Estado Social que fornece benesses assistencialistas; o processo de doação de serviços pelo Estado retira o cidadão do debate concreto sobre a construção desse Estado, que coage a liberdade, mas não justifica discursivamente essa coação e que não oferta possibilidade de crítica ao Direito por ele operado.

Kelsen almejou igualizar o Direito ao próprio Estado, mas o Estado não é ontologicamente o Direito, porém seu instrumentalizador. Se Kelsen admite que a ordem jurídica deve ser assegurada por uma autoridade reconhecida, o problema de quem é o soberano não cessa enquanto problema político. Indagando essa questão, uma das primeiras reflexões sobre o papel do soberano na Filosofia Política Moderna foi a de Maquiavel.

O príncipe no pensamento de Maquiavel deveria assumir o projeto de uma política com valores republicanos, consequências do desenvolvimento de uma concepção de natureza humana virtuosa. Todavia, Maquiavel não imputa qual seria a tarefa do humanismo para além de uma ação virtuosa realizada pelo homo politicus.

Por que o republicanismo mediterrâneo se justificaria como esforço heróico em salvar a República se nem sempre o equilíbrio de poder entre os príncipes e o povo ou com os aristocratas virtuosos é possível ? Por que aceitar a autoridade de um príncipe virtuoso sem critérios racionais para isso? O Estado concebido por Maquiavel encontra na ideia de bem comum a justificativa da ação heróica, bela, e ao mesmo tempo, trágica do príncipe. A ação virtuosa do princeps seria justificada para assegurar o interesse coletivo sobre os interesses particulares. Sua ação se justificaria no âmbito pragmático de mobilização das forças políticas do Estado para amenizar os conflitos e atingir o bem comum.

O fim de justificação do Estado leva ao nível honroso ações que seriam eticamente condenáveis. Mas essa visão, por outro lado, coloca Maquiavel em um estágio mais elevado de pensamento republicano sobre a ação estatal e suas tradições de um bem comum construído através da submissão do povo às armas e às virtudes do príncipe ${ }^{23}$, eliminando, se necessário, intermediários como a aristocracia ou a oligarquia como metas republicanas: unificação do poder estatal para referenciar a ação política, exercício de virtudes públicas e de valores políticos como o nacionalismo.

Para Kant, ao contrário de Maquiavel, a forma político-jurídica e o conjunto de 
relações formadoras do espaço público, os meios de comunicação, os jornais, a esfera literária, as faculdades acadêmicas, constituem o núcleo da esfera pública no âmbito de uma reflexão sobre a tradição política liberal, que sintetiza em grande parte a noção de uma relação reflexiva entre liberdade individual e liberdade pública. O Direito estatal serve ao fim de publicizar os juízos subjetivos dos cidadãos em uma República através da garantia da lei igualitária formalmente para todos, que é expressão da igualdade formal de todos os cidadãos como possíveis falantes do espaço público, que é o meio de externar a liberdade de expressão enquanto direito subjetivo fundamental.

A ideia de ampliação da razão pública em Kant assoma na medida em que se tem a possibilidade de uma racionalidade aberta a todos em uma sociedade democrática, onde se deveria cogitar o aproveitamento da "decadência" dos valores absolutos medievais em função da possibilidade da discussão crítica sobre os valores. Kant colocou o sujeito não como meio de fins transcendentes, mas como alguém que se reconstrói na esfera da publicidade de valores relativizados, sem referências absolutas de valor.

Os valores para Kant são concebidos em uma esfera de escolha pessoal de desejos e inclinações para depois se expressarem no espaço público de comunicação (esfera da liberdade de expressão pública) em objetos discursivos, construídos coletivamente pelo uso público do entendimento dos sujeitos capazes de entrar em consenso. O projeto kantiano de controle da Política, a 'Política Moral' desdobrou-se na construção histórica de sua institucionalização jurídica que parte do consenso de uma federação de nações para garantir coerção ao desrespeito pela pessoa humana, o que se expressa nas instituições jurídicas internacionais: ONU, Tribunal Penal Internacional.

A ideia de que os indivíduos atomizados sem referência objetiva de virtudes públicas dominantes representarão o cerne de uma democracia liberal encontra em Kant uma apropriação positiva, construtiva, ao contrário de Platão, que teme a democracia pela "decadência" dos valores. Platão considera a democracia perigosa, tumultuária e decadente. Para Platão a democracia, pela massificação do povo, cria um descompasso entre valores alienados de virtude e a normatividade ideal da justiça, bem comum etc ${ }^{24}$. Goyard-Fabre ${ }^{25}$ mostra que a visão platônica é uma posição crítica à democracia que não pode se sustentar à luz da "liberdade dos modernos", que trabalham com a relatividade dos valores circunscritos na vivência de cada sujeito.

A tradição inglesa de Estado de Direito funda-se na ideia de Locke - um Estado formado pelo corpo político dos cidadãos iguais que, portadores da razão natural como expressão da vontade de Deus em suas consciências, guiados pela senda da justiça moral, cuja expressão é a lei natural como lei moral; com a proteção de direitos individuais na linha de Locke e Kant, a tradição liberal de proteção dos direitos à liberdade de crença religiosa, à liberdade de expressão, à liberdade de ir e vir, enfim, comunga da tese da limitação do poder legislativo pelo Direito Constitucional como proteção à liberdade individual.

A tradição liberal de Locke discutia a legitimidade do soberano ao obrigá-lo a respeitar os direitos naturais. Em uma esfera de acordo de vontades, o caráter eventualmente imperfeito da execução da lei moral, por não gerar justiça efetiva entre os indivíduos, obrigaria os homens a pensarem uma lei para o corpo civil, e garantir o cumprimento das disposições morais enquanto reguladoras dos bens jurídicos envolvidos nas relações humanas. A lei jurídica adviria da esfera da própria atividade de normatização enquanto atividade exterior à autocoerção moral do sujeito e, posteriormente, do sujeito através do parlamento, votando e elegendo representantes.

À insegurança do justo moral, por não existir um critério racional de controle das ações morais dos indivíduos, projeta-se a legitimação estatal na esfera do acordo racional entre os indivíduos, que assim obteriam a segurança jurídica através da construção de um Estado legal. A partir do contrato civil só existirá liberdade política através e nos limites da lei civil autorizatória do agir ${ }^{26}$.

A ausência da discussão da legitimidade do Direito em Kelsen implicou como consequência mais grave a falta de um debate acerca da radicalização da Democracia justificadora do Estado, por não contar com um debate sobre a ideia de um núcleo moral a ser protegido pelo Estado, núcleo esse que em Kant é a própria liberdade de pensamento e 
sua capacidade de autonomia moral e jurídica.

\section{CRítica a Kelsen A PARTIR de UMA PERSPECTIVA KANTIANA}

Se, para Kant, a fundamentação do Estado se dá a partir do raciocínio de justificação em que o Estado serve para proteger o Direito dentro da possibilidade do cidadão contratualizar o pacto político ${ }^{27}$, então o cidadão não pode abdicar de sua faculdade de concessão de legitimidade ao pacto, estando aberta a capacidade de arrazoar e produzir pretensões de normatividade contra o Estado. Entende-se que na tradição liberal de Kant o cidadão mantém sua função concessiva de legitimidade e como tal criticou o Estado, e o faz privilegiadamente com base no sistema de direitos decorrentes da liberdade política fundamental prevista na Introdução à 'Doutrina do Direito'28, que é norteadora da construção do Direito em Kant.

O sistema jurídico racional concebido por Kant resguarda o sujeito político das intempéries históricas de um autoritarismo ocasional, pois a intangibilidade da pessoa humana é ao mesmo tempo uma exigência do Estado como vinculado à liberdade do indivíduo, um direito cosmopolita e um valor político (finalidade) para os Estado pactuantes, os quais se desrespeitarem o Direito Cosmopolita (Jus Cosmopoliticum) podem ser punidos como inimigos justos pelas instâncias internacionais.

No âmbito da soberania interna, Kant segue Hobbes e prima pela unidade do Estado e a pacificação pela força caso necessário, desde que a lei tenha sido votada em um parlamento que foi escolhido pelo povo. Admitindo valores subjetivos que os indivíduos dão a si mesmos, Kant pode coordenar, do ponto de vista do Estado, a iniciativa integradora entre o exterior jurídico coercitivo e o interior subjetivo privado, livre e autônomo moralmente. A solução de Kant é a universalidade do dever e respeito à pessoa humana que põe limites ao poder, à política, que, se não fosse limitada e processualizada racionalmente nas instituições, faria com que as pretensões de poder destruíssem o próprio Estado.

A função do Estado kelseniano deve ser, portanto, manter-se no horizonte da perspectiva kantiana de um Estado coercitivo que garanta o cumprimento da lei e o respeito às liberdades subjetivas sim, mas direcionado por valores e pela moralidade, superando a dicotomia Direito-Moral traçada por Max Weber em favor de uma discussão sobre a legitimidade do Direito.

Kant desenvolve uma teoria da moralidade imanente à própria História e não dependente de poderes sobrenaturais ou supra-humanos: o progresso ético está em relação com o progresso técnico, o esforço racional humano de controle e desenvolvimento das inclinações e disposições naturais é o que move a história, está afirmada uma ação valorativa que se dá como individualidade e sociabilidade criadora, ainda que conflituosa.

Para Kant, viver em sociedade é conflituoso, mas não é em vão, pois o progresso humano propiciando condições de liberdade para todos é o que faz a finalidade da ideia de humanidade adquirir sentido moral ${ }^{29}$. Mesmo a guerra teria uma função histórica positiva a fim de assegurar o sumo bem segundo Herrero ${ }^{30}$, pois leva os homens a se dispersarem pela terra, depois os leva à consciência da necessidade do estabelecimento de um contrato em prol da paz, e depois os leva a estabelecer um contrato jurídico cosmopolita.

A natureza inclina o homem a disposições que ele irá desenvolver pela razão, tal como a realização do sumo bem no mundo por ação do Direito e da Política ${ }^{31}$ com fins éticos. A imanência de uma construção histórica do Estado, decorrente inclusive da perspectiva kantiana, atinge em Kelsen um nível de positivismo estatal que chega ao ápice da pretensão de haver superado o jusnaturalismo. Todavia, é preciso criticar o positivismo burocrático no qual estacionou o Estado kelseniano.

Para Kant um tal Estado seria patrimonialista e por isso não republicano, não se pode transformar o Estado em um bem patrimonial com um governo paternalista. Apesar de atribuir ao Estado função protetora das liberdades do cidadão, em Kant "o estado é o procedimento ordenado da fixação do direito"32. O doador de leis empírico deve se mirar na justificativa e limites do Direito Racional ${ }^{33}$. 
Para Kant, o ideal de cidadania seria uma expressão individualizada e jurídica da vontade popular a partir do dado básico de uma vontade cidadã de votar. É preciso pensar um projeto filosófico de emancipação pelo Direito através da ação crítica do indivíduo com o uso de seu entendimento ao tratar dos negócios públicos. Assim, a volta à liberdade de discussão institucionalizada sobre os fundamentos de legitimação jurídico-estatal, fundamentação que se considera na linha de Kant como sintetizada na expressão da liberdade política com significado republicano e constitucional de liberdade externa, que visa todos os fins práticos possíveis ${ }^{34}$.

Prosseguir a ideia de Estado e de Direito na linha de pensamento de Kant é, pois, a defesa da liberdade individual e racional como fundação do mundo político ${ }^{35}$. Não se pode reduzir o pensamento político de Kant a um jusnaturalismo com inspiração em uma razão divina porque a racionalidade jurídica e política kantiana forma-se no seu uso prático que concretiza os princípios a priori cogitados. O que é fundamental no "Direito da Razão" de Kant é como a razão prática assume formas estatais de existência, de institucionalização de seus projetos e fins racionais de co-existência de liberdade dos indivíduos dentro de um Estado de Direito.

\section{CONCLUSÃo}

O pensamento jurídico de Kelsen foi importante para a construção de uma Ciência do Direito na primeira metade do séc. XX e em decorrência dele se fez uma interpretação positivista da relação entre Direito e Estado, afastando a pretensa construção de direitos naturais como base do Direito positivo. Todavia, essa construção de Kelsen também representou a maior teoria de afastamento da moral e da política do problema da legitimação do ordenamento jurídico. Sob a perspectiva de neutralizar o choque de valores e ideologias sobre o Direito em prol da paz e da segurança, não mais se cogitaria sobre uma avaliação do Direito estatal com base na moral e não mais se poderia perceber como a política estaria no exercício da democracia pelo cidadão.

A teoria de Kelsen abriu caminho ao publicismo e ao Direito público intervencionista sobre a liberdade individual, mas não deu soluções em termos de democracia participativa. Sob o foco de reconstrução do contratualismo a partir da segunda metade do século XX temse o objetivo maior do Direito estatal: sua recondução à defesa da liberdade política crítica. Principalmente com Habermas e Rawls o Direito racional de Kant volta a ser debatido, e por isso o colocamos como meio de reconstrução do ordenamento do Direito em função da liberdade política de criticar o Estado e de participar da vida pública, condição básica da existência do próprio Direito e sua função de emancipação política.

A crítica a Kelsen, assim, assume um contorno político e não metafísico: trata-se de reconhecer a necessidade de uma vinculação entre Direito e Política em torno do núcleo moral da liberdade política e sua expressão inafastável de dignidade humana e de liberdade de expressão de exercício do juízo crítico do cidadão ao seu soberano. Sem essa possibilidade do cidadão criticar o Estado e ser colocado no núcleo do sistema juspolítico a pureza das normas pode se tornar um frio domínio de governos insensíveis às demandas decorrentes da reinvindicação política, e pior, usando a manta do Direito puro e ordenado estatalmente como meio de camuflar eventuais abusos de poder e desrespeitos à dignidade humana.

\section{REFERÊNCIAS}

ANDERSON, P. Linhagens do Estado Absolutista. São Paulo: Brasiliense, 2004.

BARZOTTO, L. F. O positivismo jurídico contemporâneo. Uma introdução a Kelsen, Ross e Hart. São Leopoldo: Ed. Unisinos, 1999. 
BENTHAM, J. Uma introdução aos princípios da moral e da legislação. In: Os pensadores. São Paulo: Nova Cultural, 1979.

BOURGEOIS, B. Philosophie et droits de l'homme de Kant à Marx. Paris: Presse Universitaires de France, 1990.

GOYARD-FABRE, S. O que é Democracia ? São Paulo: Martins Fontes, 2003.

HERRERO, F. J. Religião e História em Kant. Tradução José A. Ceschia. São Paulo: Loyola, 1991.

HÖFFE, O. Immanuel Kant. São Paulo: Martins Fontes, 2005.

KANT, I. A Metafísica dos Costumes. Doutrina do Direito. Livro I. Tradução José Lamego. Lisboa: Calouste-Gulbenkian, 2005.

KELSEN, H. Teoría Comunista del Derecho y del Estado. Tradução Alfredo J. Weiss. Buenos Aires: Emercé, 1957.

Teoria Geral das Normas. Tradução José Florentino Duarte. Porto Alegre: Sérgio Fabris Editor, 1986. . Teoria Pura do Direito. Coimbra: Armênio Amado, 1984.

KERSTING, W. Liberdade bem-ordenada. Filosofia do Direito e do Estado de Immanuel Kant. Porto Alegre: Fabris, 2012.

. Universalismo e direitos humanos. Porto Alegre: Ed. da PUC-RS, 2003.

LOCKE, J. Dois tratados sobre o governo civil. São Paulo: Martins Fontes, 2005, vol.2.

SCHMITT, C. A crise da democracia parlamentar. Teologia Política. São Paulo: Scritta, 1996.

. El Leviathan en la teoria del Estado de Thomas Hobbes. Tradução Francisco Javier

Conde. Granada: Comares, 2004.

. Legalidade e Legitimidade. Belo Horizonte: Del Rey, 2007.

. O guardião da Constituição. Belo Horizonte: Del Rey, 2007.

VASCONCELOS, A. Teoria Pura do Direito: repasse crítico de seus principais fundamentos. Rio de Janeiro: Forense, 2003.

\section{Notas}

1 KELSEN, H. Em Teoría Comunista del Derecho y del Estado. Tradução Alfredo J. Weiss. Buenos Aires: Emercé, 1957, p.267.

2 Uma teoria da decisão implica uma teoria da vontade de poder jurídico, na qual se delineia a função do intérprete autorizado do Direito como alguém capaz de efetivar o sentido ou fím da norma, implicando a concretização ou efetividade daquilo que o legislador quis ao pronunciar um dado comando. Em toda interpretação existe um grau de decisão irredutível, que é revelado como dependente somente do arbítrio de quem decide, esse é o fundamento do que se denomina de decisionismo, como explica Carl Schmitt em Legalidade e Legitimidade. Belo Horizonte: Del Rey, 2007, p.61.

3 SCHMITT, C. O guardião da Constituição. Belo Horizonte: Del Rey, 2007, p.56.

4 SCHMITT, C. Op. Cit. p.66.

5 KELSEN, H. Teoria Pura do Direito. Coimbra: Armênio Amado, 1984, p. 68.

6 KELSEN, H. Teoria Pura do Direito. Coimbra: Armênio Amado, 1984, p. 73.

7 VASCONCELOS, A. Teoria Pura do Direito: repasse critico de seus principais fundamentos. Rio de Janeiro: Forense, 2003, p. 147.

8 VASCONCELOS, A. Op. Cit. p. 147.

9 VASCONCELOS, A. Op. Cit. p.148.

10 BENTHAM, J. Uma introdução aos princípios da moral e da legislação. In: Os pensadores. São Paulo: Nova Cultural, 1979, p.35.

11 VASCONCELOS, A. Teoria Pura do Direito: repasse crítico de seus principais fundamentos. Rio de Janeiro: Forense, 2003, p.51.

12 SCHMITT, C. El Leviathan en la teoria del Estado de Thomas Hobbes. Tradução Francisco Javier Conde. 
Granada: Comares, 2004, p.64.

13 SCHMITT C. A crise da democracia parlamentar. Teologia Política. São Paulo: Scritta, 1996, p. 89.

14 SCHMITT, C. Op. Cit. p. 90.

15 KELSEN, H. Teoria Pura do Direito. Coimbra: Armênio Amado, 1984, p.75.

16 KELSEN, H. Teoria Pura do Direito. Coimbra: Armênio Amado, 198, p.86-87.

17 Podemos dividir a obra de Kelsen em uma primeira fase até 1934 com a publicação da primeira edição da "Teoria Pura do Direito" com forte influência kantiana e da lógica da "Escola de Viena"; de 1934 a 1960 uma fase estatista, com a defesa e desenvolvimento dos pressupostos do normativismo jurídico e do relativismo axiológico, publicação de "Teoria Geral do Direito e do Estado" em 1945; e uma terceira fase, de 1960 até sua morte em 1973 com a influência decisiva do realismo jurídico dos EUA (onde viveu de 1940 a 1973) e a publicação de "Teoria Geral das Normas" em 1970, com uma forte negação da tradição kantiana em relação aos pressupostos éticos, considerando-os metafísicos.

18 KELSEN. H. Teoria Geral das Normas. Tradução José Florentino Duarte. Porto Alegre: Sérgio Fabris Editor, 1986, p.232 ss.

19 BARZOTTO, L. F. O positivismo jurídico contemporâneo. Uma introdução a Kelsen, Ross e Hart. São Leopoldo: Ed. Unisinos, 1999, p. 27.

20 BARZOTTO, L. F. Op. Cit. p. 31.

21 KELSEN, H. Teoria Pura do Direito. Coimbra: Armênio Amado, 1984, p. 35.

22 KELSEN, H. Op. Cit. p.35.

23 ANDERSON, P. Linhagens do Estado Absolutista. São Paulo: Brasiliense, 2004, p.165.

24 GOYARD-FABRE, S. O que é Democracia ? São Paulo: Martins Fontes, 2003, p.267.

25 GOYARD-FABRE, S. Op. Cit. p.71.

26 LOCKE, J. Dois tratados sobre o governo civil. São Paulo: Martins Fontes, 2005, vol.2, p.433.

27 KANT, I. A Metafísica dos Costumes. Doutrina do Direito. Livro I. Tradução José Lamego. Lisboa: Calouste-Gulbenkian, 2005, p. 43.

28 KANT, I. A Metafísica dos Costumes. Doutrina do Direito. Livro I. Tradução José Lamego. Lisboa: Calouste-Gulbenkian, 2005, p. 43.

29 HERRERO, F. J. Religião e História em Kant. Tradução José A. Ceschia. São Paulo: Loyola, 1991, p.124: "O fim do homem é ser um membro livre do reino da natureza, a "faculdade de julgar reflexionante que julga a natureza como um sistema de fins. Se o Soberano Bem a realizar-se no mundo prescreve a unificação da moralidade e da natureza, esta tem de possibilitar a concordância com a moralidade. E essa possibilidade é dada pelo conhecimento particular da natureza através da faculdade de julgar que reflete sobre suas leis particulares, para nós fortuitas, mas que são vistas como necessárias pelo princípio transcendental a priori de finalidade da natureza, pelo qual essas leis particulares são atribuídas a um entendimento, diferente do nosso, cuja intenção é que a natureza tenha uma ordem final reconhecível por nós...".

30 HERRERO, F. J. Op. Cit. p. 131.

31 HERRERO, F. J. Op. Cit. p.135.

32 KERSTING, W. Liberdade bem-ordenada. Filosofia do Direito e do Estado de Immanuel Kant. Porto Alegre: Fabris, 2012, p.318.

33 KERSTING, W. Op. Cit. p.335.

34 HÖFFE, O. Immanuel Kant. São Paulo: Martins Fontes, 2005, p. 247.

35 KERSTING, W. Universalismo e direitos humanos. Porto Alegre: Ed. da PUC-RS, 2003, p.71. Cf. BOURGEOIS, B. Philosophie et droits de l'homme de Kant à Marx. Paris: Presse Universitaires de France, 1990, p.35: Kant sintetiza o ideal de felicidade (bonheur) e os ideais deontológicos da Ética na defesa de um núcleo de direitos do homem na prática da democracia no Estado de Direito, que significa a concessão aos homens do direito de buscar seus interesses. Diz BOURGEOIS, B. Op. Cit. p.35: "Gracê à son heurese contradiction, la philosophie pratique de Kant témoignerait, en quelque sorte malgré elle, dans la culmination même en elle de la problématique idéale-libérale des droits de l'homme, pour le dépassement de celle-ci dans un accomplissement réel-démocratique d'ellemême." Kant rejeita a violência revolucionária e opta pela paz racional da proteção jurídica dos direitos humanos (BOURGEOIS, B. Op. Cit. p.35). 